\title{
Francisco López de Gómara y la Orden de Alcántara*/
}

\section{Francisco López de Gómara and the Order of Alcántara}

\section{María del Carmen Martínez Martínez}

Universidad de Valladolid

In memoriam

María Justina Sarabia Viejo

Este artículo da a conocer aspectos inéditos de la biografía de Francisco López de Gómara. Su solicitud de un hábito de religioso de la Orden de Alcántara y la consiguiente información permite aclarar su filiación, su grado de bachiller y los estudios realizados durante su estancia en Bolonia. Entre los testigos están su maestro Pedro de Rúa, antiguos compañeros del Colegio de San Clemente y algunos vecinos de la villa de Gómara.

Palabras Clave: Francisco López de Gómara; Religiosos de Órdenes Militares; Colegio de San Clemente de los Españoles; Orden de Alcántara; Siglo XVI; Cronistas.

This article brings to light new aspects concerning the biography of Francisco López de Gómara. His desire to take the religious habit of the Order of Alcántara, and the information this provides, allows us to clear up many aspects of his affiliation, his degree of bachelor, and the studies he followed during his stay in Bologna. Among the witnesses are his master, Pedro de Rúa, old companions from the Spanish College of San Clemente, and neighbours from the town of Gómara.

KeYwords: Francisco López de Gómara; Religious members of the Military Orders; The Spanish College of San Clemente; Military Order of Alcántara; Sixteenth Century; Chroniclers.

* Este trabajo es resultado de la investigación realizada en el proyecto de investigación «Tradición Clásica y Humanista en España e Hispanoamérica: narrativas no oficiales. Siglos XVIXVIII» (Ref. FFI2012-37448-C04-01), financiado por el Ministerio de Economía y Competitividad del Gobierno de España. 
Los vacíos no aclarados en la trayectoria vital de Francisco López de Gómara y las circunstancias que rodearon la escritura y difusión de $\mathrm{La}$ Historia de las Indias y conquista de México siguen mereciendo la atención de los investigadores. Las novedades, por su escasez, son de gran importancia. A la biografía más completa sobre el cronista ${ }^{1}$ se han sumado en la última década contribuciones que cuestionan su supuesta condición de capellán de Cortés ${ }^{2}$ y han revelado datos novedosos, entre ellos la declaración de López de Gómara de que conoció a Cortés cuando regresó la primera vez de la Nueva España. ${ }^{3}$ Los nuevos testimonios aquí aportados ofrecen datos hasta ahora desconocidos sobre su filiación, grado académico alcanzado y la merced de un hábito de religioso de una orden militar.

\section{La desconocida pretensión de López de Gómara}

En el siglo XVI la pertenencia a una Orden Militar deparaba no pocos beneficios a sus miembros y familiares. El mero hecho de llevar la insignia distintiva comportaba que en su persona se habían probado los requisitos exigidos. López de Gómara no fue una excepción entre los hombres de su tiempo y aspiró a un hábito, tal vez por ver en ello la oportunidad de progresar en sus aspiraciones en el mundo de las letras, al que mostró gran inclinación desde fechas tempranas, o incluso alcanzar metas mayores. La Orden elegida fue la de Alcántara y, por su condición de clérigo, el hábito solicitado fue el de religioso.

En ninguno de los estudios conocidos sobre el personaje se menciona su condición de freile, pero la merced del hábito de religioso de Alcántara debe sumarse a su biografía. Así podemos afirmarlo tras analizar las huellas documentales de su paso por el Consejo de las Órdenes. En la tarea nos ha resultado de gran utilidad el panorama trazado por Álvarez-Coca González sobre el funcionamiento del Consejo y la dispersión de la información sobre los pretendientes. Por ello, el seguimiento de los diferentes trámites obliga a la consulta de los papeles del oficio del secretario, de los escribanos de cámara, del «Archivo Secreto del Consejo» y de los archivos

1 Jiménez, 2001, 29-129.

2 Miralles Ostos, 2009.

3 Martínez Martínez, 2010, 274. 
de los respectivos conventos, ${ }^{4}$ tarea que no siempre es posible por los avatares sufridos por la documentación del Consejo y los notorios vacíos en el caso de algunas Órdenes, entre ellas la de Alcántara. ${ }^{5}$

Nuestra investigación sobre la concesión de la merced del hábito de religioso de López de Gómara se inició a partir de su información personal, conservada en el «Archivo Secreto o Privado» del Consejo. ${ }^{6}$ Curiosamente ha pasado desapercibida, sin ser relacionada, hasta donde alcanzamos, con el cronista. Su gran interés radica tanto en las novedades que aporta sobre el personaje como en la calidad de los testigos que las proporcionan. ${ }^{7}$

En los primeros días de octubre de 1543 Francisco López de Gómara se encontraba en Valladolid, donde entonces residían los Consejos. Hasta el momento es la referencia más temprana que lo sitúa en la ciudad castellana después del desastre de Argel. Sabemos que presentó en el Consejo de las Órdenes una «rrelaçión y petición» manifestando su propósito de ser freile de Alcántara y vivir en la observancia de su regla por la devoción que tenía a san Benito y a la Orden, por lo que solicitaba que se «le mandase admitir e dar el auyto e insignia della». ${ }^{8}$ La petición de López de Gómara, en la que se presentó como bachiller - primera mención conocida del grado académico alcanzado- y vecino de Soria, siguió su curso y, comprobada la veracidad de los datos expuestos, se inició el procedimiento con un real decreto al presidente del Consejo, que llevaría a este órgano colegiado a decidir la concesión. ${ }^{9}$

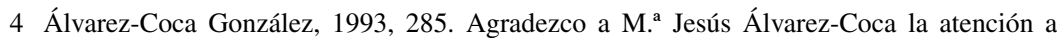
todas mis consultas sobre el funcionamiento del Consejo de las Órdenes y al personal de Sala del Archivo Histórico Nacional su orientación y ayuda. Valor Bravo, 2011, 180-190 y 205.

5 Álvarez-Coca González, 2000, 1235-1268.

6 En la portada del expediente reza «Francisco López de Gomera». Así lo recogen Pérez Castañeda y Couto de León, 1980, 139. Sobre el Archivo Secreto véase Álvarez-Coca González, 2000, 1241-1242.

7 Archivo Histórico Nacional, Madrid (AHN), Órdenes Militares (OM), ReligiososAlcántara, exp. 245 (positivo 983). Información del hábito de freile del bachiller Gómara, 1543. El expediente se encuentra entre uno de 1716 y otro de 1672, carece de numeración y consta de 10 hojas cosidas y dos sueltas (una de ellas contiene las preguntas para el examen de los testigos y la otra es un doble folio con la real provisión para hacer la información).

8 Álvarez-Coca González, 1993, 14, 286. Los conocidos son de fecha posterior al paso de López de Gómara por el Consejo de las Órdenes. Tal vez, cuando finalice la organización y descripción de los fondos del Archivo Histórico de Toledo, podamos contar con testimonios de su actuación en el siglo XVI.

9 Álvarez-Coca González, 1993, 286, advierte que, en el caso de los caballeros, el monarca podía remitirlos para su verificación a otros Consejos e incluso a la Cámara de Castilla. 
El calatravo, cronista y capellán real, frey Francisco de Rades y Andrada, señaló que los fundadores de las Órdenes Militares quisieron que, además de religiosos milites o caballeros de armas, en ellas hubiese

religiosos clérigos dedicados principalmente para el culto divino y para pelear contra los moros con armas espirituales, es a saber: con oraciones, ayunos, abstinencias y otras obras de religión. ${ }^{10}$

¿Era esa la intención de López de Gómara cuando, años después de participar en la desdichada campaña de Argel, ${ }^{11}$ solicitó el hábito de religioso de una Orden Militar? ¿Lo movían otros intereses o razones? ¿Por qué la Orden de Alcántara?

No hemos encontrado ninguna razón determinante sobre las cuestiones planteadas. En este sentido conviene recordar que justificó la escritura de las Guerras de mar, tanto por la inclinación que tenía a la historia como

Por manifestar a los extranjeros las cosas que nuestra nación ha pasado con moros, turcos y cristianos dignas de memoria. Principalmente viendo que los italianos hacen poca memoria de las cosas que los nuestros han hecho por mar contra moros en Mazalquivir, Orán, Bugia, Tripol, Gelves, Querquenes, y en otros lugares de Berbería, y que lo mismo es de las cosas entre los moros y los Barbarrojas, de los cuales hablan poco y mal por no las saber. Y que esto se muestra en poner mal los nombres de lugares, linajes y personas, según se ve en Paulo Bembo, Pablo Jovio y en Arnoldo Ferronio. Item, que es bien hacer memoria de la santa intención que los reyes y hombres de España han tenido en guerrear contra infieles, con gastos increíbles, muertes y cautiverios que infinitas personas han padecido como mártires. ${ }^{12}$

Cabe preguntarse si López de Gómara consideraba la pluma su «arma» y su «obra de religión» contra infieles, amén de que con la escritura de obras de historia aspirase a ser nombrado cronista real y por ello defendiese con sobradas razones la tradición de que lo hicieran hombres de Iglesia. ${ }^{13}$ Durante los años que residió en Italia estuvo bien informado de la amenaza que acechaba al Mediterráneo y aumentó su sensibilidad hacia el tema de moros y turcos. De hecho, dedicó su tiempo a escribir sobre aquella cuestión después de presentar su petición en el Consejo de las Órdenes. En septiembre de 1545 ya había corregido una parte de la vida de Barbarroja, pese a que algunos de sus amigos le aconsejaron que siendo «cristiano y clérigo, $1627-1631$

10 Rades y Andrada, 1572. Prólogo del autor a los lectores, s.f. Postigo Castellanos, 2000,

11 Jiménez, 2001, 95-98.

12 López de Gómara, 2000, 53-54; López de Gómara, 1989, 14.

13 Jiménez, 2001, 93. 
no había de escribir historia de turco y corsario», como advirtió en la dedicatoria que hizo del texto al marqués de Astorga. ${ }^{14}$ Los acontecimientos vividos en Argel fueron narrados como testigo, utilizando en ocasiones la primera persona, con especial dramatismo en algunos momentos, como al recordar el desbarate de la flota de España bajo los efectos de la tormenta que acabó con la mayoría de las embarcaciones al tiempo que los cristianos que alcanzaban la costa eran alanceados y otros muchos morían ahogados, situación que arrancó «mil votos a los marineros y soldados». ${ }^{15}$

Por otro lado, la visita al convento de Alcántara había puesto de manifiesto la necesidad de que los freiles supiesen gramática. ${ }^{16} \mathrm{~A}$ aquellas alturas el bachiller López sabía bien lo que suponía el estudio, el orden y la disciplina pues no en vano había pasado varios años en el Colegio de San Clemente en Bolonia. Puede que viese en la merced una ayuda para seguir cultivando su inclinación por las letras ${ }^{17}$ y la vía para aspirar al nombramiento de cronista o capellán de Su Majestad. ${ }^{18}$

También es posible que la pertenencia a la Orden de Alcántara de algún destacado personaje, a cuya protección aspiraba o gozaba, determinase su elección. En Argel estuvo presente el comendador mayor de la Orden, don Pedro de la Cueva, y el clavero, don Fadrique de Toledo. Tal vez tuviese ocasión en aquella empresa de tratar con algún clérigo distinguido con el hábito de Alcántara. ${ }^{19}$ Conviene no olvidar que en 1552, cuando López de Gómara escribió al obispo de Arras anunciándole el envío de un ejemplar de La Historia de las Indias lo hizo por mano de Luis de Ávila, ${ }^{20}$ que en 1530 formó parte del acompañamiento del emperador

14 López de Gómara, 1989, 13-14.

15 López de Gómara, 2000, 54-55; 218-219.

16 AHN, OM, L. 329c, 41-47. En los años posteriores a la solicitud de López de Gómara las cuentas del contador mayor de la Orden reflejan una partida del pago al bachiller que leía gramática. Así se comprueba en el año 1545 y en 1548, AHN, OM. L. 330c, 57 y 121: «al bachiller que liere gramática en el convento de san Benito de la dicha orden de la villa de Alcántara este dicho año catorze mil y dozientos maravedís de salario».

17 Valor Bravo, 2011, 207, destaca el ambiente de estudio en el Sacro Convento de San Benito que contaba con una importante biblioteca analizada por López de Zuazo y Algar, Martín Nieto, Miranda Díaz, 2013.

18 En aquellos años, entre los capellanes del rey eran de la Orden de Alcántara frey Pedro Gutiérrez, frey Diego de Ovando y frey Francisco Calderón.

19 AHN, OM, L. 329c, 16v. Hábito de freile de Alcántara a Antonio de Horna, clérigo. Bugía, 13 de noviembre de 1541. Tras realizar la estancia requerida en el convento de San Benito solicitó hacer profesión, Valladolid, 19 de julio de 1544 . Ibidem. $257 \mathrm{v}-258$.

20 Real Biblioteca, Madrid, Fondo Granvela II/2252, 304r, Carta de Francisco López de Gómara al cardenal Granvela, Zaragoza, 20 de noviembre de 1552. El texto de la misiva se publicó en Avisos, VIII, 32, Madrid, enero-marzo de 2003. 
cuando pasó a Italia y en cuyo registro advirtió «que después fue comendador mayor de Alcántara». ${ }^{21}$

Si tenemos en consideración el procedimiento señalado por ÁlvarezCoca, en la pretensión de los caballeros se generaban tres expedientes a su nombre: el del secretario, el del escribano de cámara de Calatrava y Alcántara, y el de pruebas. Finalizada esta primera fase se iniciaba otra que concluía con la profesión. ${ }^{22}$ En el caso de la pretensión de López de Gómara a un hábito de religioso no hemos podido reconstruir documentalmente todos los pasos.

El secretario Juan de Paredes, por acuerdo del Consejo de las Órdenes, inició de oficio las diligencias que precedían a la fase inquisitiva y el 5 de octubre de 1543 extendió una real provisión emanada del Consejo. Esta fue presentada por el interesado en la escribanía de cámara para el abono de los derechos de expedición y registro. ${ }^{23} \mathrm{Al}$ igual que en el caso de los caballeros, el pretensor a religioso era consciente con este paso del inicio del proceso con la pertinente y «discreta» averiguación sobre su persona. Para llevarla a cabo fueron comisionados Rodrigo de Torres y Juan Morales, caballeros de Santiago. ${ }^{24}$

La real provisión llegó a manos de Juan Morales, vecino y regidor de la ciudad de Soria, el 11 de octubre. Las indicaciones eran claras: concluida la fase inquisitiva, remitiría la información - firmada, cerrada y sellada de manera que hiciese fe-, para ser examinada en el Consejo y «proueer lo que deba ser proueýdo». En el interior del envío, además de la comisión para recibir personalmente la información de personas que conocieran a Francisco López de Gómara y a su linaje, encontró las preguntas para el examen de los testigos y al pie de ellas la rúbrica de los del Consejo de las Órdenes. ${ }^{25}$ Finalizada la averiguación, Morales dio cuenta por escrito de su proceder desde la recepción de la comisión, y aquel papel, la real provisión, las preguntas originales del interrogatorio y las respuestas de los testigos

21 López de Gómara, 2000, 127.

22 Álvarez-Coca González, 1993, 286-296.

23 AHN, OM, Religiosos-Alcántara, exp. 245. La señal de Juan de Paredes da cuenta de que fue registrada. De conservarse, tendría que estar en el registro del sello del Consejo de las Órdenes.

24 Ibidem. Real provisión para averiguar si en Francisco López de Gómara, vecino de Soria, concurren las calidades que se requieren para ser admitido al hábito de freile de Alcántara, Valladolid, 5 de octubre de 1543 .

25 Al pie de las preguntas figuran las rúbricas del clavero Hernando de Córdoba, el licenciado Juan Sarmiento y Ortega y las de los doctores Bernardino de Anaya, Jacobo González de Arteaga y Pedro de Goñi. 
fueron confiadas a un portador para entregarlas en mano al secretario Paredes.

Examinada la información en el Consejo de las Órdenes, se consideró que en López de Gómara concurrían las calidades requeridas para ser freile de Alcántara. Así lo traduce la anotación «fiat» y «despachada, año de 1543» que se hizo en la portada del expediente. Aquella decisión dio lugar a la expedición de la real cédula por la que se ordenaba al prior de Alcántara que le diese en el convento el hábito de freile, firmada por el príncipe Felipe en Valladolid, el 26 de octubre de 1543. ${ }^{26}$

Antes de profesar, los religiosos tenían que pasar un año en el convento de San Benito de Alcántara aprendiendo la regla y otras cosas propias de los freiles..$^{27}$ Sesenta días antes de que concluyese aquel periodo, el administrador del convento remitía al Consejo relación de sus méritos para que, si fuesen tales, permaneciese en la Orden y se diese la correspondiente cédula para ser recibido a la profesión del hábito. Según las definiciones de Alcántara, los clérigos antes de profesar eran aprobados por el Prior $^{28}$ y ancianos del convento de San Benito y luego se despachaba la correspondiente cédula de Su Majestad al prior para que, transcurrido el año de aprobación, el interesado que lo solicitase hiciese su profesión. ${ }^{29}$

El hábito de los religiosos de Alcántara era el mismo que el de los caballeros, pero largo y talar. Cuando salían del convento debían llevar lobas y capirotes o sotanas y manteos. Para cubrir la cabeza usaban bonetes sin facción alguna. En el coro y otros actos de la comunidad usaban mantos blancos. Su condición se traducía también en su cabello, pues traían abierta la corona. ${ }^{30}$

26 AHN, OM, L. 329c, 156r. Concesión del hábito de freile de Alcántara al bachiller Francisco López de Gómara, Valladolid, 26 de octubre de 1543. Se encuentra en el volumen VII del Registro de títulos, cédulas y provisiones del secretario de Calatrava y Alcántara, que contiene registros desde el 9 de febrero de 1541 al 15 de octubre de 1544. Hasta 1576 hubo dos escribanías de cámara (un escribano de Santiago y otro de Calatrava, Alcántara y Montesa). Pérez Martín, 1979, 537-540. Entre los integrantes del Consejo de Órdenes se encontraba Bernardino de Anaya, antiguo colegial de San Clemente, consejero desde 1534, y que bien pudo con su apoyo mostrar la «solidaridad colegial» con quien como él había vivido en el Colegio de los Españoles de Bolonia, máxime cuando incumplía uno de los requisitos para ingresar como religioso, la legitimidad.

27 Mendo, 1681, 185. El autor no incorporó en la obra en castellano «todas las questiones, puntos, y dificultades, que tocan a los Religiosos Militares», que incluyó en el tomo latino.

28 En aquellos momentos lo era frey Alonso de Angulo. AHN, OM, L. 329c, 50v-51. Su nombramiento se había realizado en Monzón, el 27 de agosto de 1542 en sustitución de frey Diego de Terreros, de avanzada edad para continuar como prior.

29 Difiniciones de la orden y cavallería de Alcántara, [s.a.], 19.

30 Ibidem, 11. Así se estableció en el capítulo general que se celebró en Toledo y se acabó en Madrid en 1562. 
Desconocemos si López de Gómara se trasladó al convento de Alcántara para cumplir la etapa de prueba pues en los registros no hemos localizado su cédula de profesión. ${ }^{31}$ Tampoco hay evidencias documentales de que se le concediese alguna excepción. Por ello es posible que no llegase a realizar la estancia requerida o que, si la hizo, por alguna circunstancia no solicitase la cédula de profesión o esta no fuese registrada. No hay que olvidar que el proceso requería disponer de medios para afrontar los gastos.

Es llamativo que Gómara y los que lo trataron silencien la merced real. Revisando las escasas menciones conocidas de López de Gómara entre sus contemporáneos, el único indicio lo encontramos de la mano de Páez de Castro en una carta a Jerónimo de Zurita. En aquel intercambio epistolar la figura de López se fue concretando con el paso del tiempo. Un breve repaso lo pone en evidencia. En 1546 Páez no sabía quién era Gómara..$^{32}$ A partir de 1554 se encuentra en su círculo de relaciones y reconoce abiertamente su valía como historiador de las Indias. ${ }^{33}$ En los años siguientes nos regala preciosas referencias sobre su vida en Flandes, dificultades económicas, enfermedades y sobre su trato frecuente propiciado por la vecindad. ${ }^{34}$ López de Gómara regresó a España en 1556 y volvió a coincidir con Páez en Amberes dos años más tarde. Narrando a su amigo Zurita este reencuentro se refirió a él como «Fr. López de Gómara». Todos los editores de esta carta han desarrollado la abreviatura «Fr. $\gg^{35}$ que se advierte en el original como fray, aunque sabemos que López de Gómara no era miembro de ninguna orden regu$\operatorname{lar}^{36} \mathrm{y}$, hasta donde hemos podido comprobar, acostumbraba a presentarse como «clérigo presbítero de la diócesis de Osma» ${ }^{37}$ o simplemente como

31 Esta no aparece en los registros de Calatrava y Alcántara, vols. VII a XIII desde 9 de febrero de 1541 a 24 de mayo de 1561. AHN, OM, L. 329c a 335c.

32 Domingo Malvadi, 2011, 340. Carta de Páez de Castro a Jerónimo de Zurita, Trento, 8 de junio de 1546: «La carta de Gómara para el arzobispo Gotho no se ha dado porque está ausente. Cuando venga yo la daré y enviaré la respuesta. Avíseme vuestra merced quién es Gómara».

33 Ibidem, 396-397: «Gómara, el historiador de las Indias, es vivo, aunque ha estado doliente».

34 Ibidem, 401, 420, 424. El 26 de abril de 1555, desde Bruselas, «Gómara está bueno». En agosto de ese año «está gotoso»; en septiembre, «Gómara besa las manos de vuestra merced. Está razonable y tenemos alguna esperanza que le darán algo».

35 Real Academia de la Historia (RAH), Madrid, A-112, 333r. Carta de Juan Páez de Castro a Jerónimo Zurita, Amberes, 7 de junio de 1558.

36 Como fray desarrollan la abreviatura las ediciones de Andrés, 1971, 563 y Domingo Malvadi, 2011, 435.

37 Martínez Martínez, 2010, 270-271. También recordó su condición de clérigo en su testamento, Lewis, 1984, 61-79. Como tal se presenta en la dedicatoria al marqués de Astorga de la Crónica de los corsarios Barbarroja, López de Gómara, 1989, 14. 
«clérigo estante en esta corte». ${ }^{38}$ Conocida la concesión a López de Gómara de la merced del hábito de religioso de Alcántara, sin duda, se presenta más oportuna la lectura de la abreviatura como frey.

\section{Testigos}

La Orden de Alcántara exigía a los aspirantes al hábito de religioso probar su condición de hidalgos a fuero de España o, cuando no lo eran, «ser bachilleres en Teología o Cánones, o al menos en Artes, o que, por lo menos, supiesen gramática». ${ }^{39}$ Para ser admitido también era preciso que el aspirante acreditase limpieza de sangre, que era cristiano viejo, hijo de legítimo matrimonio o que había sido legitimado.

Las preguntas para saber si concurrían las calidades contenidas en las definiciones de Alcántara trataban sobre el conocimiento que los testigos tenían del candidato, su familia, antepasados, condición, salud y formación. En el caso de López de Gómara se condensaron todos aquellos extremos en ocho preguntas a las que, después de prestar juramento, respondieron los testigos secreta y apartadamente:

I. Primeramente sy conoçen al dicho bachiller Francisco López de Gómara y de qué hedad es.

II. Yten si conoçen a su padre y a su madre e de dónde son vezinos e naturales.

III. Yten si conosçieron a sus ahuelos y ahuelas, ansý de parte de su padre como de su madre e de donde heran vecinos e naturales.

IIII. Yten si saben quel dicho vachiller Francisco López de Gómara e los dichos sus padres e ahuelos son e fueron christianos, christianos biejos sin tener mezcla alguna de conversos, judíos ni moros.

V. Yten si saben quel dicho vachiller Francisco López de Gómara es onbre de buenas costumbres, quito de malos biçios.

VI. Yten si saben que sea onbre sano que no tenga enfermedad contagiosa por do sea ynútil para el seruiçio del coro.

VII. Yten si saben quel vachiller Francisco de Gómara aya estudiado gramática o otra çiencia, e por qué tiempo, e si se ha aprovechado della y qué auilidad tiene.

VIII. Yten sy saben quel dicho vachiller Francisco de Gómara se (sic) hijo legítimo, avido de legítimo matrimonio.

38 AHN, OM, Archivo Histórico de Toledo, 42070. Petición de Francisco López de Gómara para que Bernardino de Mendoza, comendador de Bexix e Castil de Castels, de la Orden de Calatrava, le pague los 99.000 maravedís que le debía, Madrid, 27 de enero de 1553.

39 Pérez Castañeda y Couto de León, 1980, 5. 
Ninguna diferencia apreciable con otros expedientes de pretendientes al hábito de religioso de Alcántara en aquellos años. ${ }^{40} \mathrm{Con}$ el deseo de que las respuestas quedasen acreditadas el comisionado tenía que preguntar a los testigos «cómo lo sabe; e si lo cree, cómo y por qué lo cree; y sy lo oyó dezir declare a quién e cómo e qué tanto tiempo ha». Si lo hizo no lo reflejó con detalle sobre el papel.

Juan Morales se apresuró a cumplir con el encargo. Entre el 13 y el 17 de octubre de 1543 declararon en la ciudad de Soria y la villa de Gómara un selecto grupo de personas que conocía a Francisco López. Con el fin de reunir la información pertinente interrogó a once testigos, tres en la ciudad de Soria y el resto en la villa de Gómara. Buscó a personas honradas, de buen vivir y fama, que por su relación con el pretensor pudiesen responder al interrogatorio y a quienes se pudiese dar entero crédito.

El doctor Melchor de Sarabia y el clérigo Pedro Calderón fueron los primeros en declarar el 13 de octubre, en la ciudad de Soria. Dos días después lo hicieron algunos vecinos de avanzada edad (la mayoría de 60 años o más) de la villa de Gómara: Pedro Hernández de Vitas, Hernán Núñez Romero, Sancho Garcés, Diego de Hernán González, Pedro Moreno, Alonso de la Guardia, el bachiller Juan González de Sepúlveda, médico, y Andrés González, escribano público del número de la localidad. De nuevo en Soria, el 17 de octubre, lo hizo el bachiller Rúa. Excepto Hernán Núñez Romero, Sancho Garcés y Diego de Hernán González, que no sabían escribir, los testigos firmaron su declaración.

Todos habían tratado al pretendiente. El doctor Melchor de Sarabia, ${ }^{41}$ soriano de la diócesis de Osma, lo conoció en el Colegio de España en Bolonia, podría haber «ocho años poco más o menos». ${ }^{42}$ Allí, «de diez años a esta parte poco más o menos», también aseguró haber empezado a tratar-

40 AHN, OM, Religiosos-Alcántara, exp. 418, de Alonso Villarejo Remellado (1543). Las preguntas se repiten, con alguna ligera variante en virtud de la situación del pretendiente en las de Alonso Cabrera (1544), Ibidem, exp. 72 y Antonio Hurtado (1545). Ibidem, exp. 233. Antes de 1543 tan solo se conservan dos expedientes de pruebas de religiosos de Alcántara, el de Juan de Vargas Carvajal (1523), Ibidem, exp. 408 y el de Juan de Soto Aldana (1536), Ibidem, exp. 368.

41 Pérez Martín, 1979, 697. Fue admitido en San Clemente de Bolonia el 15 de enero de 1531 para estudiar Derecho Canónico. Entre 1533-1534 fue consiliario canonista y se ausentó del Colegio en septiembre de 1538, año en el que obtuvo el grado de Doctor en Derecho Civil. Barrientos Grandón, 2007, XXIX, 426-427. En 1548 fue nombrado oidor de la Audiencia de Lima y en 1565 presidente fundador de la Audiencia Real de Concepción en el Reino de Chile.

42 AHN, OM, Religiosos-Alcántara, exp. 245. Respuesta del doctor Melchor Sarabia a la primera pregunta del interrogatorio, Soria, 13 de octubre de 1543. 
lo el que fue su compañero de estudio, el clérigo Pedro Calderón..$^{43}$ Pedro Hernández de Vitas era pariente en cuarto grado de la madre de López de Gómara;44 Hernán Núñez Romero, Pedro Moreno y el bachiller Juan González de Sepúlveda lo conocían «por vista y abla después que naçió». Sancho Garcés, Diego de Hernán González, Alonso de la Guardia y Andrés González «por vista y abla y conversaçión». El bachiller Pedro de Rúa «porque a sydo su disçípulo y a estudiado con él». Al hilo de sus respuestas se desvela el pasado menos conocido de López de Gómara.

\section{Descubriendo el linaje de Francisco López de Gómara}

Los años más desconocidos del autor de La Historia de las Indias y conquista de México son los que transcurren desde su nacimiento hasta su llegada al colegio de San Clemente de Bolonia, aunque las lagunas rodean gran parte de su vida. Pese a que en Annales del Emperador Carlos Quinto recordó su nacimiento en la villa de Gómara (Soria), la mañana del domingo dos febrero de 1511, festividad de la Candelaria, ${ }^{45}$ en aquella ocasión silenció el nombre de sus progenitores. Tampoco los desveló en su testamento. ${ }^{46}$ Nora Edith Jiménez, después de buscar pistas sobre su ascendencia, escribió hace más de una década «No conocemos el nombre de los padres de nuestro personaje, y puede ser que nunca lleguemos a saberlo».47 Ahora es posible aclarar ese vacío de la mano del cronista y de algunas personas que lo conocieron.

López de Gómara dejó constancia del nombre de su padre — Juan López- en la petición que presentó en el Consejo de las Órdenes solici-

43 Ibidem. Respuesta de Pedro Calderón a la primera pregunta. Pérez Martín, 1979, 725-726. Natural de Logroño, diócesis de Calahorra, fue admitido como capellán de San Clemente el 20 de septiembre de 1533; nuevamente el 3 de noviembre de 1534 y el 30 de noviembre de 1537. El tiempo declarado por Calderón situaría López en el Colegio en 1533, fecha que en su momento apuntó como posible Jiménez, 2001, 56. Sin embargo, el tiempo señalado más bien parece responder a la referencia de la estancia de Calderón en Bolonia pues las fechas no coinciden. Calderón no ingresó en San Clemente hasta septiembre de 1533 y la segunda visita del emperador al Colegio, en la que se ha creído posible la presencia de López de Gómara, fue para la celebración de la Epifanía. A López lo conoció «capellán del dicho Colegio» lo que, según los registros del Colegio, no tiene lugar hasta mayo de 1536.

44 Ibidem. Respuesta de Pedro Hernández de Vitas a la primera pregunta del interrogatorio.

45 López de Gómara, Annales del Emperador Carlos Quinto, Biblioteca Nacional de España (Madrid), Ms. 1751, 18r. Merriman, 1912, 182. Jiménez, 2001, 32.

46 Lewis, 1984, 66 y 77. En él manifestó su deseo de ser enterrado en la Iglesia de San Juan de la villa de Gómara en «la sepoltura de mis padres», pero no aclaró sus nombres.

47 Jiménez, 2001, 29-129. 
tando la merced del hábito de religioso de Alcántara. ${ }^{48} \mathrm{Al}$ hilo de la pretensión se descubre su linaje ya que varias preguntas del interrogatorio inquirían sobre sus progenitores y ascendientes (preguntas II, III y IV). Las respuestas de los testigos permiten reconstruir su filiación al dar a conocer el nombre de sus padres y abuelos por ambas líneas, al tiempo que ratifican su condición de cristianos viejos. Nada nuevo en la información de un pretendiente. La sorpresa, en su caso, aparece cuando los testigos fueron preguntados por el origen legítimo del pretendiente. Sin duda, las respuestas habrán de ser tenidas en consideración a la hora de seguir los pasos de López de Gómara e interpretar algunos hechos, entre ellos su ingreso en San Clemente de Bolonia como capellán y los motivos por los que no alcanzó el nombramiento de cronista, para el que tenía sobrados méritos, incluso más que otros, como reconoció Páez de Castro. ${ }^{49}$

Tan solo tres testigos —el doctor Sarabia, el clérigo Calderón y el bachiller Rúa - no conocieron a sus padres y por ello no aportaron información sobre su filiación. No obstante, los dos primeros, como a todos los que pasaban por San Clemente, lo presuponían cristiano viejo, condición que ninguno de los testigos puso en duda. En este punto el bachiller Pedro de Rúa declaró que solo tenía referencia de oídas de sus progenitores y de que eran originarios de la villa de Gómara.

La filiación por ambas líneas familiares la podemos establecer a partir de las declaraciones de los testigos, entre ellos Pedro Hernández de Vitas, pariente en cuarto grado de la madre del cronista. Este afirmó que los padres de Francisco López de Gómara fueron Juan López y Mari Rodríguez, ${ }^{50}$ naturales y vecinos de Gómara. Además, su testimonio sitúa a la madre en aquellas fechas en la villa:

dijo que conoçió a su padre del dicho Francisco López, que se decía Juan López, y conoçe a su madre, que se diçe Mari Rodríguez, que agora bibe en esta villa de Gómara, y que conoçió a su padre por vecino y natural desta dicha villa y a la dicha

48 AHN, OM, Religiosos-Alcántara, exp. 245. Así se advierte en la real provisión emanada del Consejo el 5 de octubre de 1543: «Sepades quel vachiller Francisco López de Gómara, hijo de Juan López, vezino de la dicha çibdad de Soria, me hizo rrelaçión por su petición que en el mi Consejo de las Órdenes presentó».

49 Domingo Malvadi, 2011, 396-397. Carta a Jerónimo Zurita, Malinas, 17 de agosto de 1554: «que de mi voto le dieran la provisión de cronista más justamente que a otros. Vuestra merced procure que le provean, si conoce sus deudos».

50 Pérez Castañeda y Couto de León $(1980,139)$ señalan que el nombre de madre era María Ruiz o Rodríguez. 
Mari Rodríguez, su madre, la conoçe por veçina y natural de la dicha villa de Gómara. ${ }^{51}$

Varios testigos utilizaron el pasado al referirse al padre («que se decía», «conoció») y, aunque en ningún caso emplean la expresión «difunto», creemos que en esas fechas Juan López ya había fallecido.

Por lo que se refiere a sus abuelos paternos declaró que fueron Juan López y Mari Ximénez ${ }^{52}$ y, aunque no conoció a los maternos, sabía que el abuelo se llamaba Juan Rodríguez, nombre confirmado por otros testigos. Solo Sancho Garcés facilitó el de la abuela materna —Juana Rodríguez-, puntualizando que no conoció a su marido porque siempre estaba ausente de la villa. Por la aclaración hemos de pensar que no los confundía pues el resto de los testigos solo la recordaron como mujer de Juan Rodríguez. ${ }^{53}$ Todos los testigos que los conocieron coincidieron en los nombre de sus antepasados por línea paterna y algunos - Sancho Garcés, Alonso de la Guardia y Andrés González- se refirieron al abuelo como Juan López de Francisco (véase árbol genealógico). La frecuencia del apellido López en la villa de Gómara no permite averiguar por el momento la ocupación del padre y su posición en la localidad.

\section{ÁRBOL GENEALÓGICO}
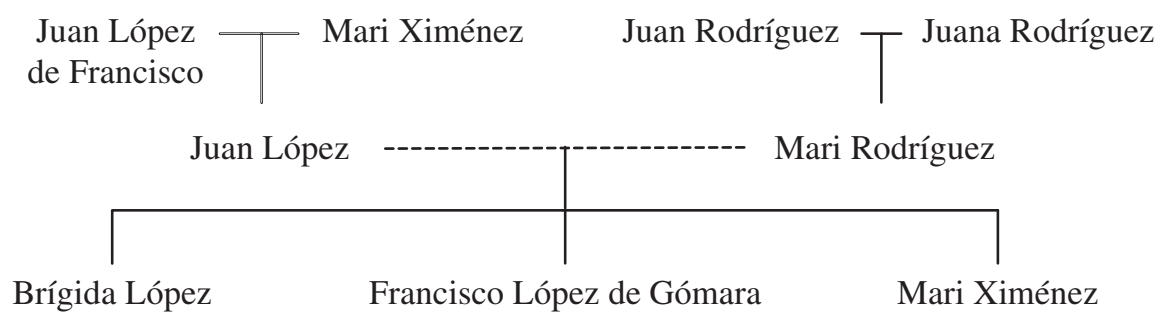

Fuente: AHN, OM, Religiosos-Alcántara, exp. 245. Elaboración propia.

51 AHN, OM, Religiosos-Alcántara, exp. 245. Respuesta de Pedro Hernández de Vitas a la segunda pregunta del interrogatorio, Gómara, 15 de octubre de 1543.

52 Ibidem. Respuesta de Pedro Hernández de Vitas a la pregunta número tres. Pérez Castañeda y Couto de León, 1980, 139, registran el nombre de la abuela paterna como María Pérez.

53 Idem. Señalan el nombre del abuelo materno como Juan Ruiz o Rodríguez, coincidiendo nuestra lectura con su segunda propuesta. 
Toda la familia tenía reputación de cristianos viejos, sin parentesco alguno con moros, judíos, ni nuevamente convertidos. Nada sospechoso sobre este aspecto en su persona para ingresar en una orden militar. Sin embargo, a excepción de sus compañeros de Bolonia, que respondieron que no la sabían porque previamente habían declarado que no conocieron a sus padres, el resto de los testigos no mostró la más mínima duda al responder a la última pregunta del interrogatorio, la que indagaba sobre su condición de hijo legítimo, una de las formalidades exigidas. Las palabras de Alonso de la Guardia y de Pedro Hernández de Vitas son claras: «no es ligýtimo ni de ligýtimo matrimonio naçido». En términos idénticos se expresó Hernán Núñez Romero. El bachiller Sepúlveda afirmó que «le tiene por bastardo», término que también brotó de los labios del escribano de la villa de Gómara: «es bastardo de los dichos su padre y madre». Incluso su maestro Rúa, ${ }^{54}$ que no conoció a sus progenitores, se hizo eco de aquella realidad al declarar «queste testigo a oýdo decir que no es legítimo».55

Carecemos de pistas para aclarar los motivos por los que Juan López no contrajo matrimonio con la madre de López de Gómara pues, según Sancho Garcés, que los conoció de mucho tiempo, «sus padres nunca fueron casados» y lo mismo repitió Pedro Moreno. En este punto cabe preguntarse si las dos hermanas mencionadas por el cronista en su testamento, Mari Ximénez (del mismo nombre que la abuela paterna) y Brígida López, ${ }^{56}$ eran también hijas de ambos, lo que parece confirmar el que las dos asumieran la filiación paterna (López y Ximénez). Tampoco disponemos de indicios para saber si Antón García, al que se refirió López en su testamento como «mi tío», era hermano de su padre o de su madre. ${ }^{57}$

Para ser ordenado tuvo que salvar su condición de hijo nacido fuera del matrimonio pues los cánones oficiales establecían que los hijos ilegítimos no podían ser clérigos ni eran idóneos para poseer beneficios. La vía para acceder a la clerecía en aquellos casos era obtener una bula papal de legitimación. Como señala Barrio Gozalo, las dispensas fueron bastan-

54 Ibidem. Respuesta del bachiller Pedro de Rúa, clérigo, a la pregunta número dos, Soria, 17 de octubre de 1543: «que no los conoze más de aver oýdo decir a su padre y que heran naturales de Gómara», reiterando lo dicho al responder a la cuarta pregunta.

55 Ibidem. Respuesta del bachiller Pedro de Rúa a la pregunta número ocho.

56 AHN, Órdenes Militares. Archivo Histórico de Toledo, 42070. En el testamento de López de Gómara es mencionada solo por su nombre pero en otros documentos que se conservan en el proceso seguido por los herederos del cronista en el Consejo de las Órdenes aparece como Brígida López, madre de Pedro Ruiz, clérigo beneficiado de la iglesia de San Juan de Gómara.

57 Lewis, 1984, 7. 
te frecuentes. ${ }^{58}$ Que López de Gómara se encontró en aquella situación lo apunta Alonso de la Guardia, al mencionar que había oído decir «questá ligytymado por bula de Su Santidad», ${ }^{59}$ lo que le habría permitido ordenarse como clérigo e ingresar en San Clemente de Bolonia como capellán.

Los testigos trazaron con palabras un retrato muy alejado de la única descripción física, casi esperpéntica, que conocemos del cronista. ${ }^{60}$ Sin duda aparentaba más edad que la que tenía (32 años) pues en opinión de la mayoría de los testigos podría tener treinta y cinco y su maestro Pedro de Rúa y el clérigo Calderón apuntan que incluso cuarenta. Era un hombre sano, al que no se le conocía enfermedad contagiosa ni dolencia que le impidiese servir en el coro. El doctor Sarabia y el clérigo Calderón recordaron que en los años que convivieron y lo trataron en el colegio de Bolonia siempre gozó de buena salud. Incluso uno de los testigos, Alonso de la Guardia, lo calificó de «hombre reçio», ${ }^{61}$ expresión que traducía que no padecía enfermedad ni presentaba defecto físico pues era «de buena complisyón». ${ }^{62}$ Años después, su estado de salud se dibuja de forma bien diferente en la correspondencia de Páez de Castro. ${ }^{63}$ A su condición física sin tachas todos los testigos añadieron que era hombre de buenas costumbres y fama. El carácter curioso de López no pasó desapercibido para sus vecinos, al igual que su comportamiento alejado de todo vicio. Tampoco

58 Barrio Gozalo, 2008, 313.

59 AHN, OM, Religiosos-Alcántara, exp. 245. Respuesta de Alonso de la Guardia a la octava pregunta, Gómara, 15 de octubre de 1543.

60 Jiménez de la Espada, [circa 1888], 9-10. Carta de Mauricio de la Cuadra a Jerónimo de Zurita. Amberes, 8 de julio de 1558.

61 AHN, OM, Religiosos-Alcántara, exp. 245. Respuesta de Alonso de la Guardia a la sexta pregunta del interrogatorio. Lewis, 1984, XLIV, 173, 66. Entre los testigos del testamento de Gómara se lee el nombre de Alonso de la Guardia, que se repite en la pesquisa que se hizo en Gómara el 5 de octubre de 1572 cuando se ordenó la recogida de los papeles del cronista y que Lewis apunta que estaba casado con una sobrina de Pedro de Rúa. Creemos que este, al igual que el Pedro Moreno que declara en la información, son homónimos de los que aparecen en el testamento. ¿Tal vez sus padres o parientes? El Pedro Moreno mencionado en el testamento era su cuñado, marido de su hermana Mari Ximénez.

62 Ibidem. Respuesta de Andrés González a la sexta pregunta, Gómara, 15 de octubre de 1543.

63 Domingo Malvadi, 2011, 425. A Jerónimo Zurita, Bruselas, 13 de diciembre de 1555: «Gómara está malo, aunque anda por estas calles, pero con esperanza de merced». Ibidem, 429, Bruselas, 4 de mayo de 1556: «Gómara ha estado muy malo, de una goma que se le hizo en la cabeza, y ya está fuera de peligro, sacáronle muchas cascas de la cabeza. Piensa partir por todo mayo. Diéronle 250 escudos de ayuda de costa para tornarse; creo que andando el tiempo le darán algo; ahora atenderá a vivir...». 
olvidaron elogiar sus méritos intelectuales al calificarlo de «hombre doto, ábil y sufiçiente», ${ }^{64}$ «doto y sabio» ${ }^{65} \mathrm{y}$ «sabio y entendido». ${ }^{66}$

\section{Una formación bien aprovechada e inclinada a cosas de virtud y letras}

Una de los aspectos más interesante de la trayectoria intelectual de López de Gómara es su formación en España e Italia. Sobre aquellos años profundizó Nora E. Jiménez; ${ }^{67}$ lo conocido se enriquece ahora con los testimonios de los testigos en la información para su ingreso como religioso en la Orden de Alcántara. Una de las preguntas del interrogatorio, la séptima, trataba sobre las habilidades y el aprovechamiento en los estudios del pretensor.

López de Gómara inició su formación a edad temprana, momento en el que quedó trazado su destino. El testigo Alonso de la Guardia afirmó que había estudiado mucho tiempo gramática, desde que era de edad de siete $\mathrm{u}$ ocho años. ${ }^{68}$ Es probable que aprendiese las primeras letras en Gómara y que luego se trasladase a Soria, donde desde 1522 enseñaba en la Colegiata de San Pedro el maestro Rúa. Así podría deducirse del testimonio de Pedro Moreno que afirmó haberlo visto estudiar «en esta tierra», probablemente refiriéndose al «Estudio de Soria» que dirigía Rúa, y que sabía de su paso por San Clemente:

a estudiado mucho tiempo porqueste testigo le bio estudiar en esta tierra y después sabe que fue al colesyo de Bolonia a donde estudió y sabe que [ha] aprobechado en él el estudio porqueste testigo le a visto predicar y declarar el ebangelio en la yglesia desta dicha villa y le tiene por honbre doto y sabio y que sabe que a estudiado de más de quince años a esta parte. ${ }^{69}$

Para los vecinos de Gómara su dedicación al estudio era una realidad conocida. La mayoría tenía noticias de su estancia en Bolonia y lo veían

64 AHN, OM, Religiosos-Alcántara, exp. 245. Respuesta de Alonso de la Guardia a la séptima pregunta, Gómara, 15 de octubre de 1543.

65 Ibidem. Respuesta del bachiller Sepúlveda a la sexta pregunta.

66 Ibidem. Respuesta de Pedro Hernández de Vitas a la séptima pregunta.

67 Jiménez, 2001, 37-93.

68 AHN, OM, Religiosos-Alcántara, exp. 245. Declaración de Alonso de la Guardia a la séptima pregunta del interrogatorio, Gómara, 15 de octubre de 1543.

69 Ibidem. Declaración de Pedro Moreno a la séptima pregunta del interrogatorio. 
predicar el evangelio e impartir doctrina en la iglesia de la localidad, de ahí la opinión generalizada de que era muy buen clérigo «y que se a aprobechado mucho en el estudio y estudios donde a estado». ${ }^{70}$ Sus testimonios así lo confirman. El bachiller Juan González de Sepúlveda, médico en la villa, puntualizó que había «estudiado gramática de más de quinçe años a esta parte» y que luego fue a «estar en el estudio y colesyo de Bolonia» aprovechando muy bien aquellos años, razón por la que lo consideraba un hombre docto, sabio y hábil. ${ }^{71}$ El lejano pariente Hernández de Vitas, declaró que había estudiado en Estudios Generales que no concretó y que oyó decir que estuvo en Bolonia. En idénticos términos se expresó Hernán Núñez Romero, quien reconoció que «no sabe que arte ni çiençia a estudiado mas de que tiene por çierto que se a aprobechado en el estudio y tiene buena abilidad y sufiçiençia». ${ }^{72}$

Ninguno de los testigos facilita pistas sobre el Estudio en el que se formó Gómara en España ni sobre dónde obtuvo el grado de bachiller que declaró en su petición, arrojando luz sobre un aspecto desconocido en su trayectoria. El dato no es fácil de rastrear, como se advierte en los casos de otros destacados hombres de letras contemporáneos. Mientras que no aparezca ningún testimonio que lo corrobore se puede conjeturar que bien pudo alcanzar el grado de bachiller en cualquiera de los centros a los que se acostumbraba acudir en la época, entre ellos Alcalá —donde lo obtuvo su maestro Pedro de Rúa, que firmaba como bachelarius Rúa—, Sigüenza o Salamanca.

Sin duda la trayectoria de Francisco López se definió con su decisión de ser un hombre de Iglesia. Las disposiciones canónicas situaban la edad mínima para recibir la tonsura en siete años y en doce para ser admitido como acólito. Si consideramos la declaración de los testigos, coincidiría con el momento en el que se inició en los estudios. Francisco López tuvo a su cargo la capellanía instituida por su tío Antón García con la obligación de atenderla en la forma prevista por el fundador percibiendo a cambio las rentas que constituían su dotación. Por las referencias facilitadas por López en su testamento se trataría de una capellanía familiar o de sangre, en la que en la fundación se llamaba al patronato activo y a gozar del pasivo al pariente más cercano del fundador o a un familiar determinado. ${ }^{73} \mathrm{El}$

\footnotetext{
70 Ibidem. Declaración de Sancho Garcés a la séptima pregunta del interrogatorio.

71 Ibidem. Declaración del bachiller Sepúlveda a la séptima pregunta del interrogatorio.

72 Ibidem. Declaración de Hernán Núñez Romero a la séptima pregunta del interrogatorio.

73 Barrio Gozalo, 2010, 62; Lewis, 1984, 78; Jiménez, 2001, 34.
} 
candidato a un beneficio simple sin cura de almas tenía que haber cumplido los catorce años, ser clérigo (haber recibido al menos la tonsura) y tener el nivel cultural adecuado. ${ }^{74}$

Sabemos que en octubre de 1535 se le concedió licencia para ausentarse durante diez años de la diócesis de Osma «en atención a su amor por las letras» y que en mayo del año siguiente fue recibido como capellán en el colegio de San Clemente de Bolonia. ${ }^{75}$ En aquellos momentos tenía veinticinco años, la establecida para recibir el presbiterado. La institución del cardenal Albornoz acogió desde su fundación a alumnos brillantes y distinguidos. Los estatutos establecían los requisitos que debían reunir los aspirantes: ser español, cristiano viejo, hijo de legítimo matrimonio, haber estudiado en una Universidad o Estudio General, estar en posesión del título de bachiller en ambos derechos, filosofía o teología, no tener una renta superior a 50 escudos anuales y ser propuesto por alguno de los obispados peninsulares con derecho de presentación de candidatos o por un miembro del linaje Albornoz. ${ }^{76}$ Recordemos además que los estatutos de 1522 incluyeron la novedad de que todos los colegiales debían probar que eran hijos de legítimo matrimonio. ${ }^{77}$

Nora E. Jiménez se preguntó sobre las razones que llevaron a López de Gómara a ingresar como capellán y no como colegial. En el intento de responder a la pregunta señaló que tal vez no reunía todos los requisitos necesarios, apuntando: «el único que pudiera faltarle sería el grado de bachiller de algún Estudio». ${ }^{78}$ De lo que no cabe duda es que no era hijo de legítimo matrimonio, por lo que no podía acreditar aquel requisito. Ello justificaría su ingreso en San Clemente como capellán y no como colegial. ${ }^{79}$ La legitimación papal le permitió ser ordenado y su condición de clérigo le abrió la puerta del Colegio.

74 Barrio Gozalo, 2008, 298-299. Barrio Gozalo, 2010, 57-66, ofrece un panorama de los beneficios parroquiales y capellanías.

75 Pérez Martín, 1979, 739-740. Las letras testimoniales a favor de Francisco López se expidieron en Gómara (diócesis de Osma), el 3 de octubre de 1535, y fue recibido como capellán el 17 de mayo del año siguiente. Jiménez, 2001, 57.

76 Cuart Moner, 1979; Jiménez, 2001, 55.

77 Cuart Moner, 1991, 59.

78 Jiménez, 2001, 57.

79 Pérez Martín, 1979, 740, llama la atención de que en las segundas pruebas de colegiales por él encargadas se le denomina colegial en vez de capellán, aunque cree que nunca llegó a gozar en el Colegio de aquella categoría. Tal vez era la manera de que reflejar sobre el papel que la comisión la había realizado un colegial, como se acostumbraba. 
En la comunidad colegial la percepción de que sus miembros respondían al perfil de los Estatutos se manifiesta con claridad en la declaración de Pedro Calderón. ${ }^{80}$ Este antiguo capellán de San Clemente — condición que por cierto no recordó en su declaración-, al evocar el paso de López por el Colegio, hizo especial hincapié en destacar la limpieza de sangre de los miembros de la comunidad colegial, aunque son bien conocidas las estrategias para disimular los linajes y cómo colegiales de linaje judeoconverso sortearon lo dispuesto ${ }^{81}$ Las palabras de Calderón traducían la ascendencia sin tacha del de López de Gómara y la confianza que mereció al encargársele las segundas pruebas sobre la limpieza de algunos de sus miembros, ${ }^{82}$ confiada habitualmente a otros colegiales, y por ello, afirmó que aunque

no conoçió a sus padres ni aguelos más de que le tiene al dicho Francisco López por christiano viejo porque si no lo fuera no le admitieran ni acogieran en el dicho colesyo de Bolonia, que no acoxen en él sy no a christianos viejos, y como a tal le dieron cargo de hazer çiertas probanças en España ques ofiçio que se suele cometer a colesyales del dicho colesyo y no a otras personas. ${ }^{83}$

De aquella comisión colegial también supieron algunos de los vecinos de la villa de Gómara, por la que pasó cuando regresó a España, probablemente en los últimos meses de 1537, después de las informaciones recibidas en Zaragoza. ${ }^{84}$ En este sentido, Andrés González, escribano de la villa, afirmó que «este testigo le bio benir a esta tierra y a esta villa [a] hacer çiertas probanças y entender en çiertos negoçios por el dicho colesyo de Bolonia». ${ }^{85}$

Por su parte, Melchor de Sarabia, admitido como colegial para estudiar Derecho Canónico el 15 de enero de $1531,{ }^{86}$ declaró en 1543

80 Ibidem. 725-726. Pedro Calderón, natural de Logroño, diócesis de Calahorra, fue admitido como capellán el 20 de septiembre de 1533. En la misma plaza lo sería también el 3 de noviembre de 1534 y el 30 de noviembre de 1537. Su estancia en San Clemente se comprueba hasta el curso $1537-$ 1538, siendo admitido en su puesto Pedro Cónsul, el 14 de mayo de 1538.

81 Cuart Moner, 1991, 60.

82 Jiménez, 2001, 67. Entre el 26 de noviembre de 1537 y el 26 de septiembre de 1538 recorrió los caminos de España para efectuar las probanzas encomendadas.

83 AHN, OM, Religiosos-Alcántara, exp. 245. Respuesta de Pedro Calderón, clérigo, a la cuarta pregunta.

84 Jiménez, 2001, 66-79. Reconstruye el itinerario de su viaje por la península desde su salida de San Clemente, el 31 de octubre de 1537, hasta su regreso, el 14 de diciembre del año siguiente.

85 Ibidem. Respuesta de Andrés González a la séptima pregunta.

86 Pérez Martín, 1979, 697-698. Entre 1532-1533 fue consiliario canonista y se ausentó del Colegio el 19 de septiembre de 1538, días después de obtener el título de Doctor en Derecho Civil. Barrientos Grandón, 2007, 426-427. 
que conoze al dicho bachiller Francisco López de Gómara por vista e abla e conversaçión que con él a tenido y tiene y que puede aver que le començó a conozer ocho años poco más o menos y le conoçió en el colesyo d España en Bolonia, capellán del dicho colesyio, donde este testigo hera colesyal en el dicho tiempo y después le conoçió en Nápoles y después que vino le conoze este testigo en España. ${ }^{87}$

Las referencias que proporciona coinciden «más o menos» con el ingreso de López en San Clemente, registrado en el Libro de admisiones del Colegio, el 17 de mayo de 1536, siendo rector Antonio de Barahona. ${ }^{88}$ Esta declaración tiene el valor añadido de situar a López de Gómara en Nápoles, escenario hasta ahora no incluido en sus andanzas italianas de las que se conocía su presencia en Roma, Bolonia y Venecia. ${ }^{89} \mathrm{Su}$ estancia allí tuvo que producirse después de su paso por Venecia, tal vez antes de embarcarse para la campaña de Argel, en la que como clérigo podría atender las necesidades espirituales y religiosas de los que acudían a la jornada. ${ }^{90}$

Las obligaciones de los capellanes en el Colegio estaban definidas en los Estatutos. Compartían con los colegiales algunas dependencias del edificio y sus celdas en nada diferían de las de aquellos. Además de encargarse de la biblioteca de la institución, de leer y cantar en el oficio Divino, cuidaban de las necesidades espirituales de los colegiales, celebraban las misas prescritas y rezaban las oraciones en la mesa. ${ }^{91}$

Está claro que López de Gómara hizo compatibles aquellas actividades con el aprovechamiento intelectual, reconocido también en los estatutos del Colegio a los capellanes. Así lo confirman los testimonios de sus compañeros. Melchor de Sarabia, recibido como doctor durante su etapa

87 AHN, OM, Religiosos-Alcántara, exp. 245. Respuesta de Melchor de Sarabia a la primera pregunta.

88 En Annales, en la información correspondiente a 1536, recogió el nombramiento de cronista del doctor Juan Ginés de Sepúlveda en Roma. Merriman, 1912, 233.

89 Jiménez, 2001, 43-53 y 81-93. Puede que en Nápoles también coincidiese con el antiguo colegial Lorenzo Polo, nombrado oidor general de Santa Clara en 1541. Polo había sido presentado en junio de 1534 por el obispo y cabildo de Osma y López de Gómara se ocupó de hacer sus segundas pruebas en Lantadilla, el 18 de julio de 1538. Permaneció en el Colegio hasta finales de agosto de 1538 y fue quien como rector del Colegio admitió como capellán a Pedro de Cónsul, que ocupó la plaza de capellán de Pedro Calderón. Pérez Martín, 1979, 731-732.

90 Sarabia abandonó el Colegio en septiembre de 1538. En aquellos momentos López de Gómara se encontraba en España realizando las segundas pruebas de varios colegiales. Ambos coincidieron en San Clemente desde el ingreso de López, el 17 de mayo de 1536, hasta el 31 de octubre de 1537. Francisco López regresó a San Clemente el 15 de diciembre de 1538, meses después de haberlo dejado el doctor Sarabia.

91 Jiménez, 2001, 58. 
colegial, desgrana las materias que siguió, incluyendo, además del latín, el griego, al declarar que durante el tiempo que coincidieron en Bolonia

Francisco López a estudiado gramática y griego y filosofýa todo el tienpo qu estubo en el dicho colesyo de Bolonia, que pudo ser quatro o çinco años, y que en las dichas facultades aprobechó bien en este tienpo y después acá a aprobechado y quel dicho Francisco López es abil y sufyçiente en las dichas facultades y esto sabe este testigo porque, como dicho tiene, se las vio estudiar estando colesyal en el dicho colesyo de Bolonia. ${ }^{92}$

En relación con la mención al estudio del latín y del griego, López de Gómara tuvo la oportunidad de disfrutar en Venecia de los fondos de la biblioteca de Diego Hurtado de Mendoza, que contaba con una variada muestra de manuscritos latinos y griegos. ${ }^{93}$ El clérigo Pedro Calderón, también capellán y compañero de estudio en San Clemente, reconoció el aprovechamiento en aquellos años en los que estudió

gramática y humanidad y esto sabe este testigo porque se lo vio estudiar en las dichas facultades todo el tienpo que estuvo en el dicho colesyo y sabe este testigo que dello sacó mucho porbecho. ${ }^{94}$

Tanto Sarabia como Calderón utilizan el término facultad, que puede remitir tanto a una disciplina concreta como al cuerpo colegiado o asociación de individuos que cultivaban una determinada disciplina. ${ }^{95}$ El Estudio de Bolonia contaba desde comienzos del siglo XVI con «estudios de humanidad», en los que se impartían materias como artes o teología. ${ }^{96}$

Pero, sin duda, el testimonio más relevante sobre su formación y progresos lo proporciona Pedro de Rúa, que recordó lo que había estudiado

92 AHN, OM, Religiosos-Alcántara, exp. 245. Respuesta de Melchor de Sarabia a la séptima pregunta, Soria, 13 de octubre de 1543.

93 Jiménez, 2001, 88-89, ofrece la relación de los libros editados antes de 1540 que formaron parte de la biblioteca del embajador Hurtado de Mendoza, entre ellos: «Tito Livio, Suetonio, Quintiliano, Tácito, Valerio Máximo, Ammiano Marcelino, Tucídices, y Flavio Josefo; varias versiones de los Discursos y el De oratore de Cicerón; la Historia Natural de Plinio (en edición de Aldo Manucio), la Geografía de Ptolomeo y el tratado De Sphaera de Juan de Sacrobosco».

94 Pedro Calderón no mencionó que él también fue capellán en San Clemente. Pérez Martín, 1979, 2, 725-726, 747. En aquella plaza fue admitido el 20 de septiembre de 1533; el 3 de noviembre de 1534 y el 30 de noviembre de 1537. El 14 de mayo de 1538 ocupó su puesto Pedro de Cónsul.

95 González González, 2005, 59-60. En los estatutos de Bolonia con frecuencia se refieren a la "facultad" de anatomía o a la de lógica o gramática o aun de notaría. El número de facultades universitarias se fijó en cinco (artes, medicina, teología, derecho civil y derecho canónico), aunque no todas contaron con ese número.

96 Jiménez, 2000, 33. 
con él. Aquel proceso de transmisión del conocimiento fue reconocido por López de Gómara al recordarlo como «mi maestro». ${ }^{97}$ La relación maestrodiscípulo, probablemente mantenida durante la estancia en Italia, continuó al regreso de Bolonia y Rúa pudo comprobar personalmente sus avances. La satisfacción por el aprovechamiento en el estudio no se oculta, dándonos cuenta de los estudios realizados y los méritos alcanzados:

sabe quel dicho bachiller Francisco López de Gómara a estudiado latín y que sabe muy bien gramática e ystorias y poesía y artes de humanidad porque estudió con este testigo; y después sabe que a estudiado en Bolonia y después que de Bolonia vino a platicado con él en cosas d estudio e a rreçebido cartas en latýn buenas, por do syente que entiende muy bien y a aprobechado en las dichas facultades y que tiene buena abilidad. ${ }^{98}$

El testimonio de Pedro de Rúa, autor de obras de prosa y poesía en latín, abre el abanico de la amplia formación que recibió López de Gómara. En ella destacaba la enseñanza de textos de la antigüedad clásica y de la lengua latina, en la que fundamentaba el escribir y hablar bien. ${ }^{99}$ Lo aprendido en la Colegiata de San Pedro de Soria, las virtudes del discípulo y el nivel alcanzado lo revelaban «sus cartas en latýn buenas» y las conversaciones sobre cosas de estudio a su regreso de Bolonia. Aunque Lewis apuntó que no es de creer que Rúa haya sido el único maestro con el que estudió, ${ }^{100}$ la declaración de Rúa no traduce que Francisco López estuviese en ningún otro Estudio antes de trasladarse a San Clemente.

Con Rúa perfeccionó López de Gómara el latín, dominio del que el maestro se mostraba complacido y que siguió utilizando pese a la amplia difusión de sus textos en romance. Así lo advirtió en la dedicatoria al marqués de Astorga de la Crónica de los Barbarrojas ${ }^{101}$ y a los impresores de La Historia de las Indias y Conquista de México. ${ }^{102}$

Fue en Soria, con el maestro Rúa, donde estudió «ystorias», como recordó este último. Del amplio conocimiento de autores que con el paso

97 Merriman, 1912, 245, Annales del emperador, 66v, año 1545.

98 AHN, OM, Religiosos-Alcántara, exp. 245. Respuesta de Pedro de Rúa a la séptima pregunta.

99 Jiménez, 2001, 41.

100 Lewis, 1984, 74.

101 López de Gómara, 1989, 18: «yo con el favor y mandado de V. S ${ }^{\mathrm{a}}$ imprimirlo ahora en romance, y de aquí a poco en latín, pues la mayor parte tengo ya hecha... Escribo en romance lo que escribo en latín».

102 López de Gómara, 1552. En la advertencia a los trasladadores: «También los aviso cómo compongo estas historias en latín para que no tomen trabajo en ello». Jiménez, 2001, 141-153. 
del tiempo conoció y utilizó dan cuenta todos sus escritos. ${ }^{103}$ Sirva una breve muestra de ejemplo. En Annales, como puso de manifiesto Merriman cuando editó el texto, registró nombres y obras (Antonio de Guevara, Bernaldo del Busto, Jerónimo de Zurita, Cristóbal Calvete de Estrella y Juan Páez de Castro) y el texto revela que conocía lo escrito por Andrés Bernáldez, Hernando del Pulgar, Pedro Mexía, Lorenzo Galíndez de Carvajal, Paulo Jovio, Pietro Bembo, Arnauld le Ferron y Jean Bronchel. ${ }^{104}$ Otros muchos aparecen en la dedicatoria de los Corsarios Barbarroja (san Jerónimo, Séneca, Pedro Mexía, Alejo Venegas, fray Alonso Venero...), en las Guerras de mar (Juan Bautista Mantuano, Bernardo Gentil, Juan Ginés de Sepúlveda, Polidoro Virgilio, Agustín Giustiniano, Diodoro Sículo, Plutarco, Plinio, Fregoso, etc. ${ }^{105}$ y en La Historia de las Indias y conquista de México (Gonzalo Fernández de Oviedo, Fernando Cortés, Pedro Mártir de Anglería, Olaus Magno). Las lecturas, los años de estudio en Bolonia, y el trato con la élite letrada, tanto en Italia como en España, ampliaron su formación.

La concesión del hábito de religioso de Alcántara, del que no parece haber hecho ostentación Francisco López de Gómara, cubre algunas de las lagunas que hasta ahora han rodeado al cronista. Tal vez no estaba tan interesado en ejercer como tal como en ser distinguido con aquella merced real, que en su caso bien podría servir para diluir su origen ilegítimo. $\mathrm{Su}$ difuminado perfil biográfico se sigue definiendo con nuevos trazos.

Recibido el 1 de abril de 2014 Aceptado el 22 de septiembre de 2014

\section{Bibliografía}

Álvarez-Coca González, María Jesús: «La concesión de hábitos de caballeros de las Órdenes Militares: procedimiento y reflejo documental (s. XVI-XIX)», Cuadernos de Historia Moderna, 14, Madrid, 1993, 277-297.

Álvarez-Coca González, María Jesús: «El Consejo de las Órdenes Militares». Cuadernos de Historia Moderna, 15, Madrid, 1994, 297-323.

103 Jiménez, 2001, 155-180, ofrece un interesante, esclarecedor y documentado panorama sobre lo que suponía escribir Historia en la época y sobre las fuentes doctrinales de López de Gómara. 104 Merriman, 1912, XXXI, XXXIII Y XXXVIII.

105 López de Gómara, 2000, 55-56. 
Alvarez-Coca González, María Jesús: «El Consejo de las Ordenes y el Archivo Histórico Nacional. Historia de una excepción al sistema archivístico de la Administración», en López-Salazar Pérez, Jerónimo (coord.), Las Órdenes Militares en la Península Ibérica, vol. II. Edad Moderna, Cuenca, Ediciones de la Universidad de Castilla-La Mancha; Cortes de Castilla-La Mancha, 2000, 1235-1268.

Andrés, Gregorio de (ed.): «31 Cartas inéditas de Juan Páez de Castro, Cronista de Carlos V», Boletín de la Real Academia de la Historia, 168-3, Madrid, 1971, 515-571.

Barrientos Grandón, Javier: «Melchor Bravo de Sarabia (1512-1577), primer miembro del Colegio de San Clemente de Bolonia en la judicatura indiana, y su familia de togados», Revista de Estudios Histórico-Jurídicos. Sección Historia del Derecho Indiano, XXIX, Valparaíso, Chile, 2007, 423-436.

Barrio Gozalo, Maximiliano: «Muchos clérigos y pocos curas. El acceso a la clerecía y a los beneficios menores en la España Moderna», Cuadernos de Investigación Histórica, 25, Madrid, 2008, 293-331.

Barrio Gozalo, Maximiliano: El sistema beneficial de la iglesia española en el Antiguo Régimen (1475-1834), Alicante, Publicaciones de la Universidad de Alicante, 2010.

Cuart, Baltasar: Colegiales mayores y limpieza de sangre durante la Edad Moderna: el estatuto de San Clemente de Bolonia, Salamanca, Universidad de Salamanca, 1991.

Difiniciones de la Orden y Cavallería de Alcantara con la historia y origen della, s.l. s.a.

Domingo Malvadi, Arantxa: Bibliofilia humanista en tiempos de Felipe II. La Biblioteca de Juan Páez de Castro, Salamanca, Universidad de Salamanca, 2011.

González González, Enrique: «Artes liberales y facultades de artes en el antiguo régimen. El orden de los saberes escolares», en González González, Enrique (coord.), Estudios y estudiantes de Filosofía. De la Facultad de Artes a la Facultad de Filosofía y Letras (1551-1929), México, Universidad Nacional Autónoma de México, 2008, 29-82.

Jiménez, Nora Edith: «Francisco López de Gómara y la musa Mediterránea. El Compendio de lo que trata Francisco López en el libro que hizo de las Guerras de mar de sus tiempos», en López de Gómara, Francisco, Guerras de mar del Emperador Carlos V, ed. de Miguel Ángel de Bunes Ibarra y Nora Edith Jiménez, Madrid, Sociedad Estatal para la Conmemoración de los Centenarios de Felipe II y Carlos V, 2000, 29-48.

Jiménez, Nora Edith: Francisco López de Gómara. Escribir historias en tiempos de Carlos V, Zamora, Michoacán, El Colegio de Michoacán, Instituto Nacional de Antropología e Historia de México, 2001. 
Jiménez de la Espada, Marcos: De un curioso percance que tuvo en Anvers el presbítero López de Gómara, por Don... Madrid, Imprenta Fontanet, S.A. [circa 1888].

Lewis, Robert E.: «El testamento de Francisco López de Gómara y otros documentos tocantes a su vida y obra», Revista de Indias, 44-173, Madrid, 1984, 61-79.

López de Gómara, Francisco: La Istoria de las Indias y conquista de México, Zaragoza, Agustín Millán, 1552.

López de Gómara, Francisco: Crónica de los corsarios Barbarroja, Madrid, Ediciones Polifemo, 1989.

López de Gómara, Francisco: Guerras de mar del Emperador Carlos V. Edición y estudio de Miguel Ángel de Bunes Ibarra y Nora Edith Jiménez, Madrid, Sociedad Estatal para la Conmemoración de los Centenarios de Felipe II y Carlos V, 2000.

López de Zuazo y Algar, José María; Martín Nieto, Dionisio A. y Miranda Díaz, Bartolomé: La librería del convento de San Benito de la Orden de Alcántara. Librerías, lectores y libros de un tesoro bibliográfico descompuesto, Mérida, Editora Regional de Extremadura, 2013.

Martínez Martínez, M. ${ }^{a}$ del Carmen: «Francisco López de Gómara y Hernán Cortés: nuevos testimonios de la relación del cronista con los marqueses del Valle de Oaxaca», Anuario de Estudios Americanos, 67-1, Sevilla, 2010, 267-302.

Martínez Millán, José (dir.): La corte de Carlos V. Los Consejos y los consejeros de Carlos V, Madrid, Sociedad Estatal para la Conmemoración de los Centenarios de Felipe II y Carlos V, 2000, vol. III.

Mendo, Andrés (S.I.): De las Órdenes militares, de svs principios, gobierno, privilegios, obligaciones, y de todos los casos morales que pertenecen a los cavalleros y religiosos de las mismas Órdenes, Madrid, Imprenta de Iuan Garcia Infançon, 1681.

Merriman, Roger Bigelow (ed.): Annals of the emperor Charles $V$ by Francisco López de Gómara, Oxforf, Clarendon Press, 1912.

Miralles Ostos, Juan: «Gómara ¿capellán de Cortés?», Boletín de la Real Academia de la Historia, 206-2, Madrid, 2009, 165-176.

Pérez Castañeda, M. ${ }^{a}$ Ángeles y Couto de León, M. ${ }^{a}$ Dolores: Pruebas para el ingreso de religiosos en las Órdenes de Calatrava, Alcántara y Montesa, Madrid, Ministerio de Cultura, 1980.

Pérez Martín, Antonio: Proles Aegidiana, 2. Los colegiales desde 1501 a 1600, Studia Albornotiana XXXI, Bolonia, Publicaciones del Real Colegio de España, 1979.

Postigo Castellanos, Elena: «Las Órdenes Militares de la Monarquía Hispana. Modelos discursivos de los siglos XVI-XVII», en López-Salazar Pérez, 
Jerónimo (coord.), Las Ordenes Militares en la Península Ibérica, vol. II. Edad Moderna, Cuenca, Ediciones de la Universidad de Castilla-La Mancha, Cortes de Castilla-La Mancha, 2000, 1585-1636.

Torres Tapia, Alfonso: Crónica de la Orden de Alcántara, Madrid, Imprenta de don Gabriel Ramírez, Impresor de la Real Academia de San Fernando, 1783, tomo 2 .

Rades y Andrada, Francisco de: Chronica de las tres Ordenes y Cauallerias de Santiago, Calatrava y Alcantara, Toledo, Iuan de Ayala, 1572. [Hay edición facsímil, con estudio sobre «La obra histórica de Rades y Andrada» por Derek Lomax, en Barcelona, El Albir, 1980.]

Valor Bravo, Diego: La Orden de Alcántara, San Sebastián, Nerea, 2011. 